\title{
Modeling the Hot Ductility of AA6061 Aluminum Alloy After Severe Plastic Deformation
}

\author{
A.A. KHAMEI, ${ }^{1,3}$ K. DEHGHANI, ${ }^{1,4}$ and R. MAHMUDI ${ }^{2}$ \\ 1.--Mining and Metallurgical Engineering Department, Amirkabir University of Technology, \\ 15914 Tehran, Iran. 2.-School of Metallurgical and Materials Engineering, College of Engineering, \\ University of Tehran, Tehran, Iran. 3.—e-mail: khamei@aut.ac.ir. 4.—e-mail: dehghani@aut.ac.ir
}

Solutionized AA6061 aluminum alloy was processed by equal-channel angular pressing followed by cold rolling. The hot ductility of the material was studied after severe plastic deformation. The hot tensile tests were carried out in the temperature range of $300-500^{\circ} \mathrm{C}$ and at the strain rates of $0.0005-0.01 \mathrm{~s}^{-1}$. Depending on the temperature and strain rate, the applied strain level exhibited significant effects on the hot ductility, strain-rate sensitivity, and activation energy. It can be suggested that the possible mechanism dominated the hot deformation during tensile testing is dynamic recovery and dislocation creep. Constitutive equations were developed to model the hot ductility of the severe plastic deformed AA6061 alloy.

\section{INTRODUCTION}

During the last two decades, severe plastic deformation (SPD) techniques have been introduced as practical approaches to produce ultrafine grain (UFG)

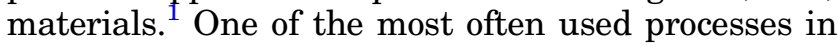
this regard is equal-channel angular pressing (ECAP), which provides an opportunity for producing bulk UFG materials, although its application has remained in the laboratory scales. ${ }^{2}$ Also, because of the limits dictated by ECAP, the shapes and sizes of the workpieces are far from the semifinal products required for industrial applications. Therefore, additional processes such as rolling, extrusion, or forging are necessary to process the equal-channel angular pressed products closer to the shapes needed for industrial applications. ${ }^{3}$ For example, the combined process of ECAP and cold rolling (CR) is anticipated not only to reduce the number of ECAP passes but also to fabricate the $\mathrm{u}$ sheets or plates. ${ }^{4}$ The effect of $\mathrm{CR}$ after ECAP on the properties and microstructure has been studied for different materials such as copper, ${ }^{5}$ aluminum, ${ }^{6}$ and titanium alloys. ${ }^{7}$ It was shown that CR after ECAP resulted in further grain refinement and improved strength ${ }^{8}$ with properties and dimensions suitable for many industrial applications. ${ }^{9,10}$ However, formability is one of the most import characteristics of materials to attain the required near-net shape and high quality for finished products. ${ }^{11}$ The flow stress during hot working can be a function of the deforma- tion parameters: i.e., strain, strain rate, and temperature. In this regard, various constitutive equations were developed based on the experimental data to describe the sensitivity of the flow stress to the strain, strain rate, and temperature. ${ }^{12}$

Among aluminum alloys, AA6061 has received great interest as one of the materials for the automobile, aerospace and construction industries. ${ }^{13}$ Incidentally, there are only few reports on the hot ductility of ultrafine-grained AA6061 alloy, and thus, this study pursues three aims. First, the combination of the ECAP and CR techniques was used to produce large ultrafine-grained strips for industrial applications. Second, the effects of parameters such as strain rate and temperature on the hot ductility of ultrafinegrained samples were studied. Third, a mathematical model was developed to predict the flow stress of the ultrafine-grained material as a function of applied strain, strain rate, and deformation temperature.

\section{MATERIALS AND METHODS}

The as-received material was AA6061 and the composition is summarized in Table I. The large workpiece subjected to ECAP had the dimensions of $100 \times$ $100 \times 14 \mathrm{~mm}^{3}$. It was homogenized at $833 \mathrm{~K}\left(530^{\circ} \mathrm{C}\right)$ for $4 \mathrm{~h}$ followed by water cooling. The ECAP was performed using route $C_{x}$. After two passes of ECAP, the samples were subjected to $90 \%$ reduction by CR at room temperature. The produced ultrafine-grained sheets 
Table I. The composition of the studied AA6061 (wt.\%)

\begin{tabular}{ccccccc}
\hline $\mathbf{S i}$ & $\mathbf{F e}$ & $\frac{\mathbf{C u}}{\mathbf{M n}}$ & $\frac{\mathbf{M g}}{\mathbf{C r}}$ & $\frac{\mathbf{A l}}{\mathrm{Bal}}$ \\
\hline 0.73 & 0.37 & 0.2 & 0.07 & 0.9 & 0.19 & . \\
\hline
\end{tabular}

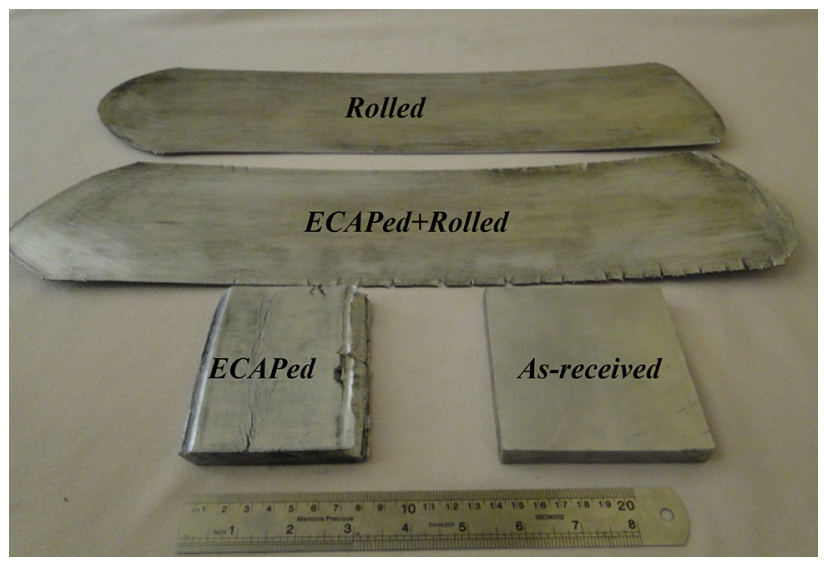

Fig. 1. As-received, equal-channel angular pressed, equal-channel angular pressed +cold rolled, and rolled samples of the AA6061 alloy. after the ECAP and CR are shown in Fig. 1. To study the hot ductility of the ultrafine-grained sheet, tensile tests were carried out using the specimens with a gauge length of $31 \mathrm{~mm}$, a width of $6 \mathrm{~mm}$, and a thickness of $1.5 \mathrm{~mm}$. The tests were carried out at the initial strain rates of $0.0005-0.01 \mathrm{~s}^{-1}$ and at 300$500^{\circ} \mathrm{C}$ (i.e., at $0.67-0.9 T_{\mathrm{m}}$, where $T_{\mathrm{m}}$ is the absolute melting point of the AA6061 alloy). Before the tests, the specimens were held for $15 \mathrm{~min}$ at the deformation temperature to eliminate the thermal gradients as well as to ensure the uniform temperature of specimens. The true stress-true strain curves were plotted using the load-displacement data.

\section{RESULTS AND DISCUSSION}

Flow Curves and Flow Stresses

Figure 2 illustrates the stress-strain curves of the heavily deformed AA6061 alloy tested under various
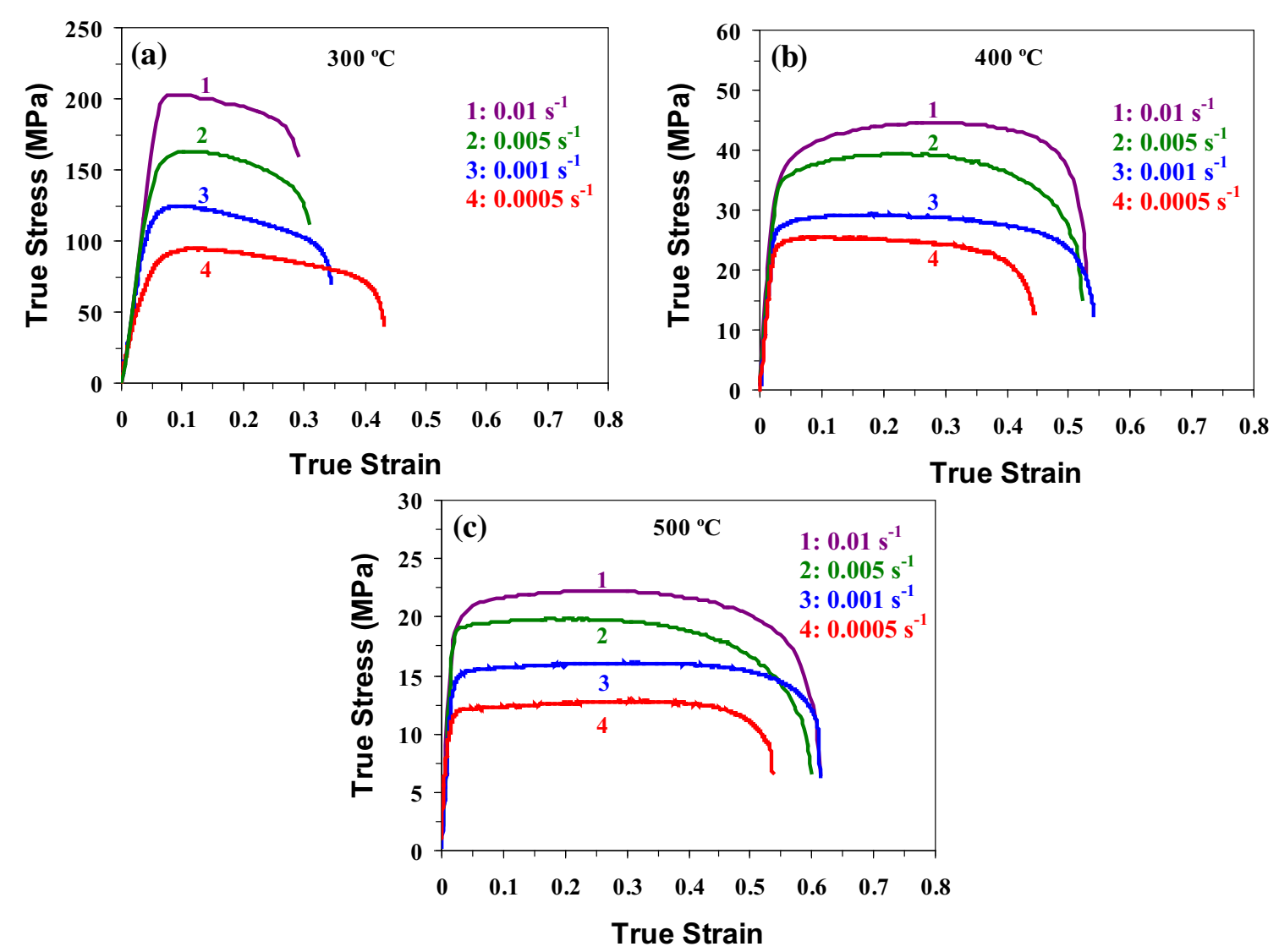

Fig. 2. Typical true stress-true strain curves of the heavily deformed alloy obtained at different strain rates and temperatures: $(\mathrm{a}) 300^{\circ} \mathrm{C}$, (b) $400^{\circ} \mathrm{C}$, and (c) $500^{\circ} \mathrm{C}$. 

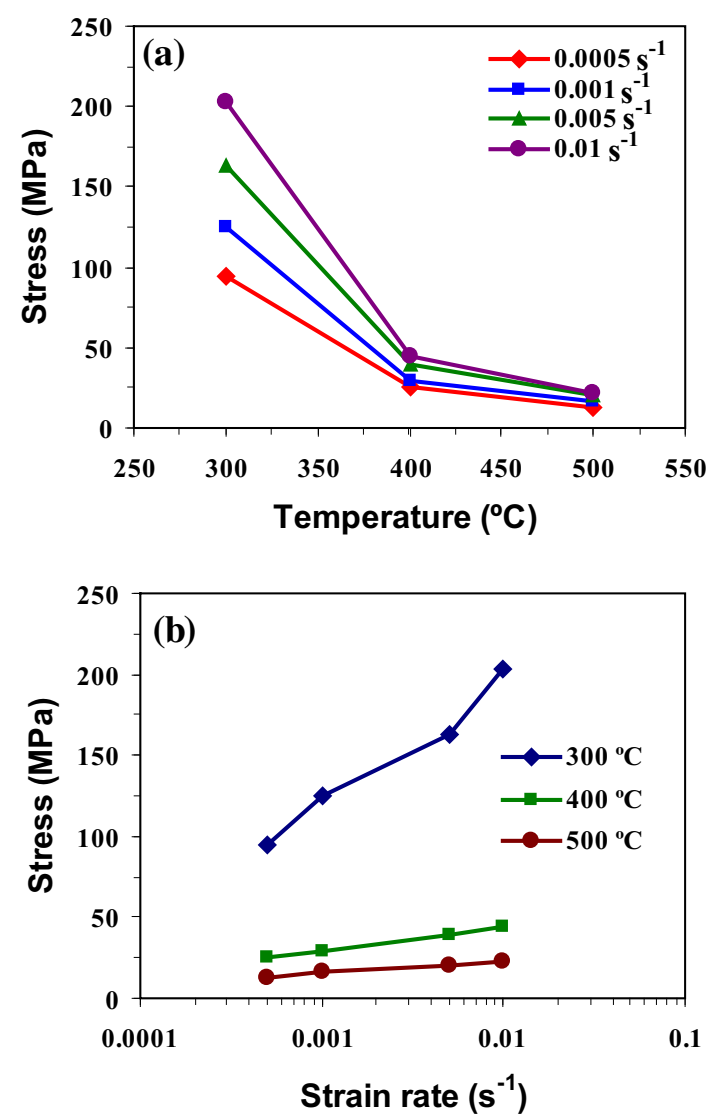

Fig. 3. Effect of the processing parameters on the peak stress: (a) effect of the deformation temperature and (b) effect of the strain rate.

conditions. Obviously, the flow stress is affected strongly by the testing temperature and applied strain rate. At a given strain rate, the effect of temperature on the flow stress is significant, indicating the hightemperature sensitivity at $300^{\circ} \mathrm{C}$ to $400^{\circ} \mathrm{C}$. Referring to Fig. 3, the peak stress increases with increasing the strain rate and decreasing the temperature. It is known that at temperatures above $0.4 T_{\mathrm{m}}$, plastic deformation is strongly influenced by thermally activated mechanisms so that the flow stress becomes temperature and strain rate dependent. ${ }^{14}$ The current results show the significant effect of temperature and strain rate on the hot behavior of ECAP + cold-rolled samples. At $573 \mathrm{~K}$, the dependence of peak stress on the strain rate is considerable. It is reported that the strength of materials decreases with temperature because the critical resolved shear stress decreases sharply with an increase in the temperature. ${ }^{15}$

\section{Elongation to Failure}

The hot ductility of the undeformed and deformed samples is compared in Fig. 4. According to this figure, at least three behaviors can be distinguished. First, the elongation of the alloy depends strongly on the severity of applied strain. The ductility of the

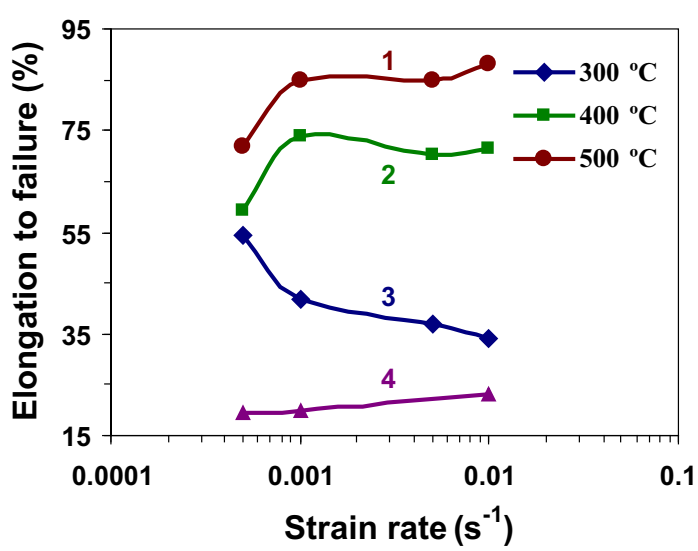

Fig. 4. Variation of elongation to failure with strain rate for the deformed alloy $(1,2,3)$ and the as-received alloy (4).

severe plastic deformed conditions is significantly higher than that of the as-received material, mainly because of a decrease in grain size ${ }^{16}$ or an increase in the grain-boundary area. ${ }^{17}$ Our findings are consistent with those reported in the literature, indicating that the hot ductility of equal-channel angular pressed AA6061 is two to four times greater than those of the unequal-channel angular pressed condition. ${ }^{18}$ Second, the ductility of severe plastic deformed samples increases with temperature. The observed behavior can be attributed to the occurrence of recovery and recrystallization during the deformation of severely deformed materials. However, the increase in temperature may also cause microstructural changes such as precipitation, strain aging, or grain growth that may affect this general behavior. ${ }^{1}$ Third, with increasing the temperature, the maximum in elongation values shifted to higher strain rates, especially at $500^{\circ} \mathrm{C}$. This trend has also been observed during the deformation of severe plastic deformed alloys such as AA7034, ${ }^{19}$ ZK60 magnesium alloy, ${ }^{20}$ and Ti-6Al$4 \mathrm{~V} .{ }^{21}$

The high elongations obtained at higher strain rates at $400^{\circ} \mathrm{C}$ and $500^{\circ} \mathrm{C}$ may be due to grain boundary sliding (GBS) during the hot deformation. ${ }^{22}$ GBS is a well-known mechanism to justify the high ductility of the ultrafine-grained materials. In addition to the development of ultrafine-grained microstructure, the structural homogeneity of the severe plastic deformed samples and their thermal stability can support the reported results. ${ }^{23}$

\section{Strain-Rate Sensitivity}

The strain-rate sensitivity index $(m)$ is an important material property that affects the formability of materials, especially at high temperatures. ${ }^{24}$ Figure 5 shows the variation of $\ln (\sigma)$ with $\ln (\dot{\varepsilon})$ at different deformation temperatures. The slope of the 
lines represents the value of the strain-rate sensitivity index. The parameter $m$ is given by:

$$
\left.m=1 / n=\frac{\partial \ln \sigma}{\partial \ln \dot{\varepsilon}}\right)_{T, \varepsilon} .
$$

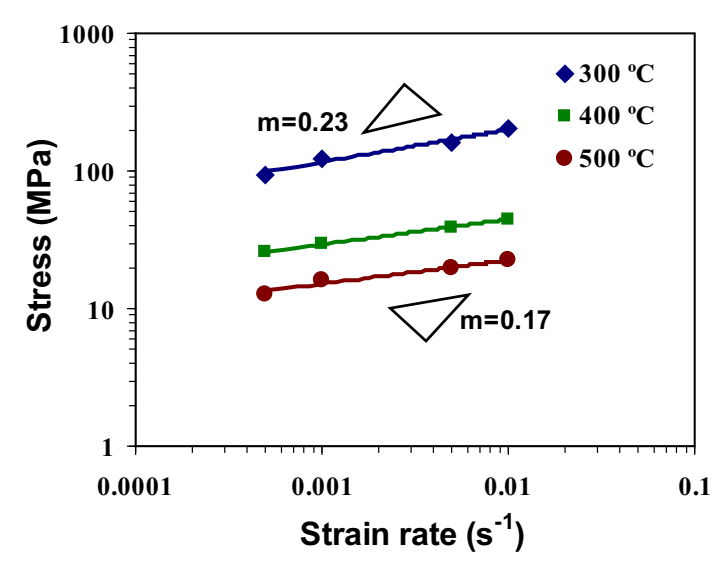

Fig. 5. Variation of flow stress with strain rate at different temperatures of the ECAP + CR alloy.
From Fig. 5, it can be found that the $m$ value is not constant in the temperature range of 300$500^{\circ} \mathrm{C}$. While the average strain-rate sensitivity index of the severe plastic deformed alloy was about 0.193, the strain-rate sensitivity index of the as-received sample was 0.098 at $400^{\circ} \mathrm{C}$. In general, the elongation to failure is increased with increasing $m$ value. $^{25}$ Thus, high strain-rate sensitivity indices lead to higher postnecking elongation or superplasticity. ${ }^{1}$ The obtained results show that the strain-rate sensitivity index depends on the dominant deformation mechanisms. ${ }^{26}$ Our $m$ values may suggest that the deformation mechanism is related to conventional dynamic recovery (DRV) and/or controlled dislocation creep. ${ }^{27}$ However, when $m$ is about 0.3 , the dominant mechanism is viscous process or intragranular glide process. ${ }^{28}$ As for the $m$ of 0.5 , the GBS has been reported to be responsible for the superplastic behavior. ${ }^{29}$ It has been reported that during the hot tensile testing of aluminum alloys, the elongation values of about $100 \%$, corresponding to the strain-rate sensitivity of about $0.2-0.25$, can be attributed to the dislocation climb mechanism. $^{18}$
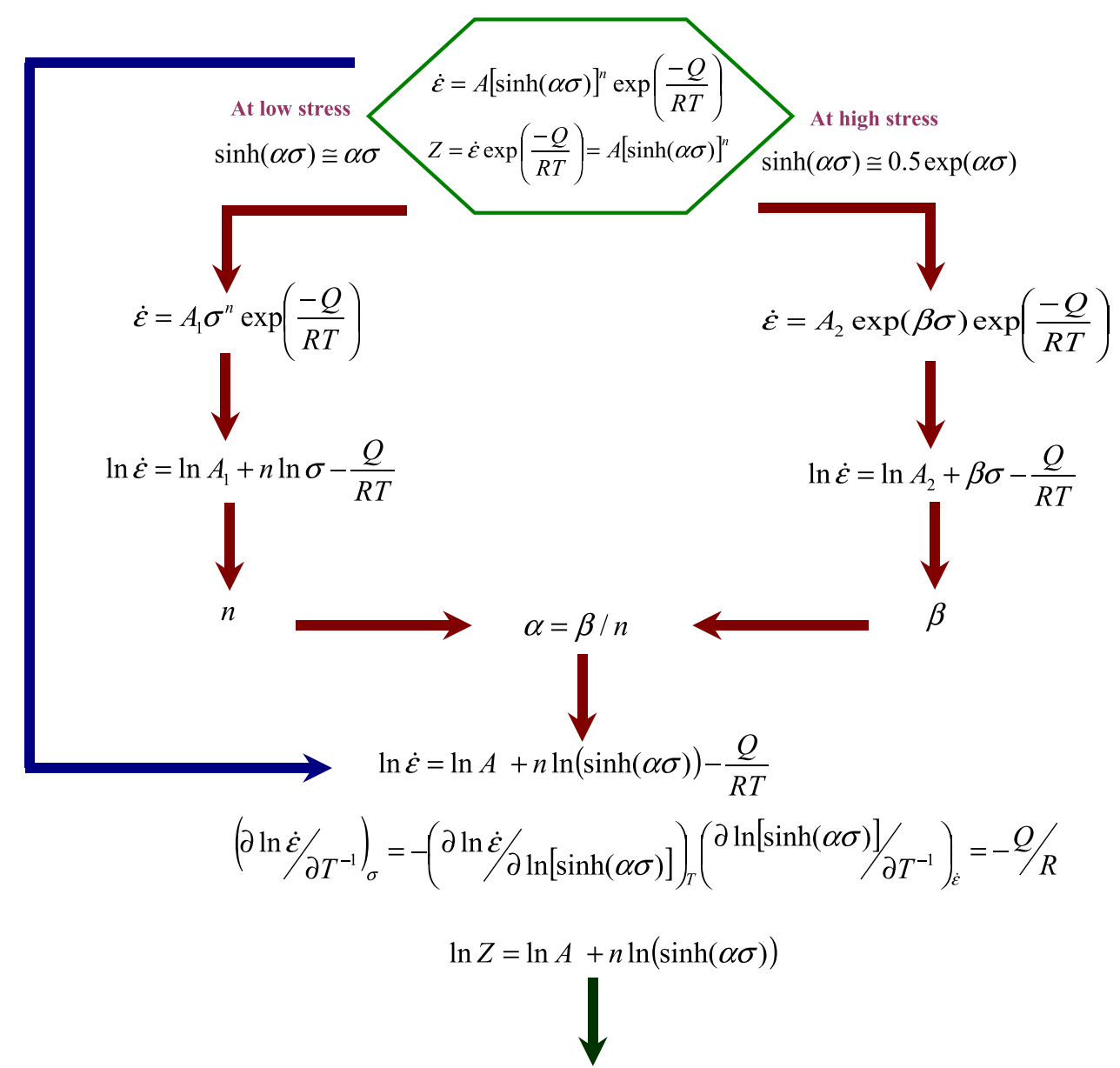

$n, \alpha, Q, A$

Fig. 6. Flow diagram of the constitutive equation. 

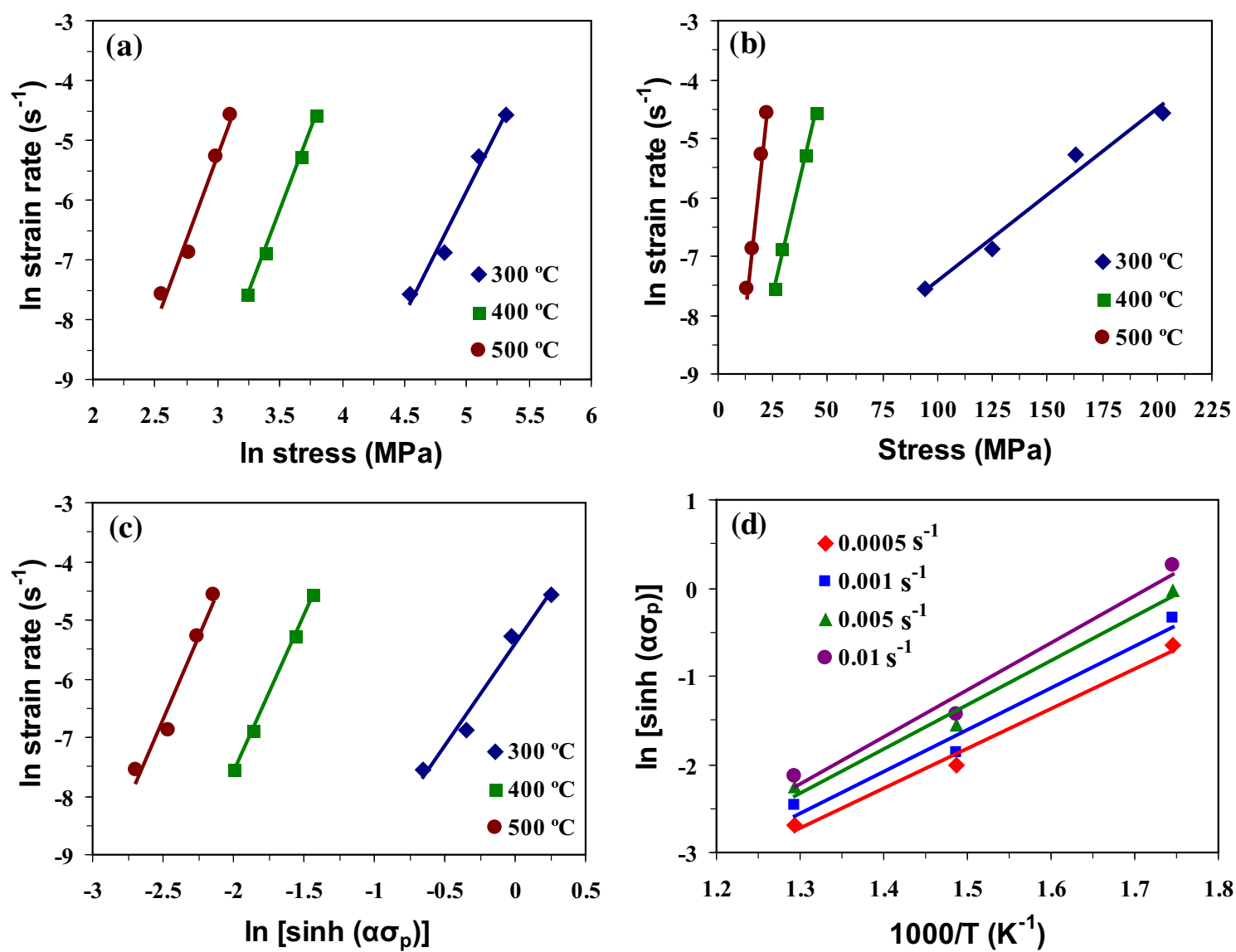

Fig. 7. Relationships among strain rate, peak stress, and deformation temperature to calculate: $(a, b) \alpha$ and $(c, d)$ activation energy $(Q)$.

\section{Constitutive Equations}

The Arrhenius-type equation, Eq. 2, is widely used to describe the hot deformation behavior of alloys during hot shear, ${ }^{30-32}$ hot compression, ${ }^{33-35}$ and hot tension ${ }^{36-38}$ tests:

$$
\dot{\varepsilon}=A[\sinh (\alpha \sigma)]^{n} \exp (-Q / R T),
$$

where $\dot{\varepsilon}$ is the strain rate $\left(\mathrm{s}^{-1}\right), R$ the universal gas constant $\left(8.314 \mathrm{~J} \mathrm{~mol}^{-1} \mathrm{~K}^{-1}\right), T$ the absolute temperature $(\mathrm{K}), Q$ is the activation energy related to the deformation mechanisms occurring during hot form$\operatorname{ing}\left(\mathrm{J} \mathrm{mol}^{-1}\right), \sigma$ is the peak stress (MPa), and $A, \alpha$, and $n$ are the material constants. Besides, the relationship between temperature and strain rate during the hot deformation of materials can be expressed by the Zener-Hollomon parameter as follows:

$$
Z=\dot{\varepsilon} \exp (Q / R T)=A[\sinh (\alpha \sigma)]^{n} .
$$

Considering the definition of the hyperbolic law, the flow stress dependence of temperature and strain rate (i.e., Zener-Hollomon parameter) is generally given by:

$$
\sigma=\frac{1}{\alpha} \ln \left\{\left(\frac{Z}{A}\right)^{1 / n}+\sqrt{\left(\frac{Z}{A}\right)^{2 / n}+1}\right\} .
$$

Figure 6 illustrates the flow chart used to calculate the values of $n, \alpha, Q$, and $A$. The values of $n$ and $\beta$ can be obtained from the slopes of the lines plotted in Fig. 7a and b, respectively. The value of $\alpha$ can be computed from $n$ and $\beta$ as: $\alpha=\beta / n=5.3 \times 10^{-3}$ $\mathrm{MPa}^{-1}$. As for the value of $Q$, it is derived from the slope of $\ln \dot{\varepsilon}-\ln [\sinh (\alpha \sigma)] \quad$ (Fig. 7c) and $\ln [\sinh (\alpha \sigma)]-T^{-1} \times 10^{-3}$ plots (Fig. $7 \mathrm{~d}$ ). The average activation energy was found to be $196.835 \mathrm{~kJ} \mathrm{~mol}^{-1}$ here. Now, $Z$ can be calculated by substituting the strain rates, temperatures, and activation energy into Eq. 3. Referring to Fig. 8, by plotting $\ln Z-\ln [\sinh (\alpha \sigma)]$, the value of $A$ can be computed as $6.26 \times 10^{15} \mathrm{~s}^{-1}$. Finally, by substituting the values of $n, A$, and $Q$ into Eqs. 2, 3, and (4), the new relationships for the hot deformation of severe plastic deformed AA6061 alloy can be developed. These are as follows: 


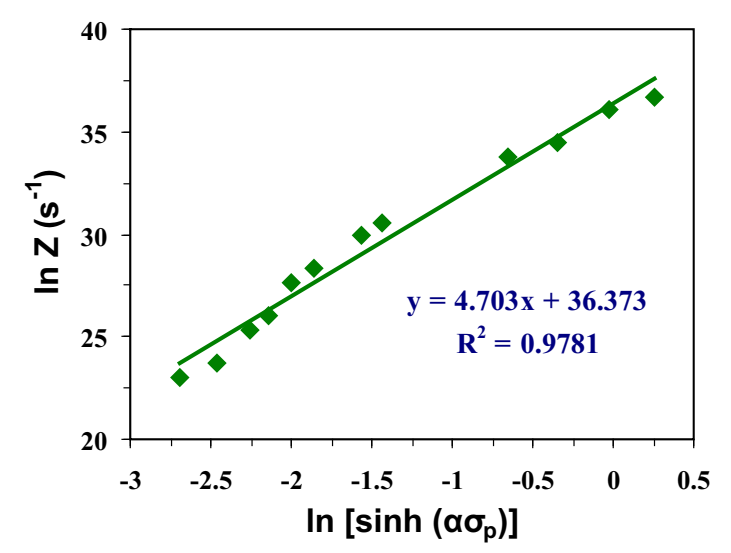

Fig. 8. Relationships between the Zener-Hollomon parameter and peak stress $(\ln Z-\ln [\sinh (\alpha \sigma)]$ plot).

$$
\dot{\varepsilon}=6.26 \times 10^{15}\left[\sinh \left(5.3 \times 10^{-3} \sigma\right)\right]^{5.06} \exp \left(-\frac{196,835}{R T}\right)
$$

$$
\begin{aligned}
Z= & \dot{\varepsilon} \exp \left(\frac{196,835}{R T}\right)=6.26 \\
& \times 10^{15}\left[\sinh \left(5.3 \times 10^{-3} \sigma\right)\right]^{5.06} \\
\sigma= & 188.68 \ln \left\{\left(\frac{Z}{6.26 \times 10^{15}}\right)^{\frac{1}{5.06}}\right. \\
& \left.+\left[\left(\frac{Z}{6.26 \times 10^{15}}\right)^{\frac{2}{5.06}}+1\right]^{1 / 2}\right\}
\end{aligned}
$$

As a thermally activated process, the hot deformation of AA6061 alloy requires an apparent activation energy that can be used as a criterion for the hot formability. ${ }^{39}$ Figure 9 shows the variation in the activation energy with the strain rate and temperature. Referring to Fig. 9a and b, it is obvious that the effects of deformation temperature and strain rate on the activation energy are significant under all conditions. As can be observed, the activation energy increases with increasing the temperature. However, at lower temperatures, i.e., $300-400^{\circ} \mathrm{C}$, the rate of increase in activation energy is different from that at higher temperatures, i.e., $400-500^{\circ} \mathrm{C}$. In fact, compared with lower temperatures, the changes in $Q$ are more sensitive to temperature at higher temperatures. According to Fig. 9, the effect of temperature on activation energy seems to be greater than the effect of strain rate. The complicated dependency of $Q$ on temperature and strain rate during hot deformation of the alloy can be attributed to the operation of different mechanisms. As depicted in Fig. 9, the value of $Q$ lies in a range of $132-250 \mathrm{~kJ} \mathrm{~mol}^{-1}$. The great
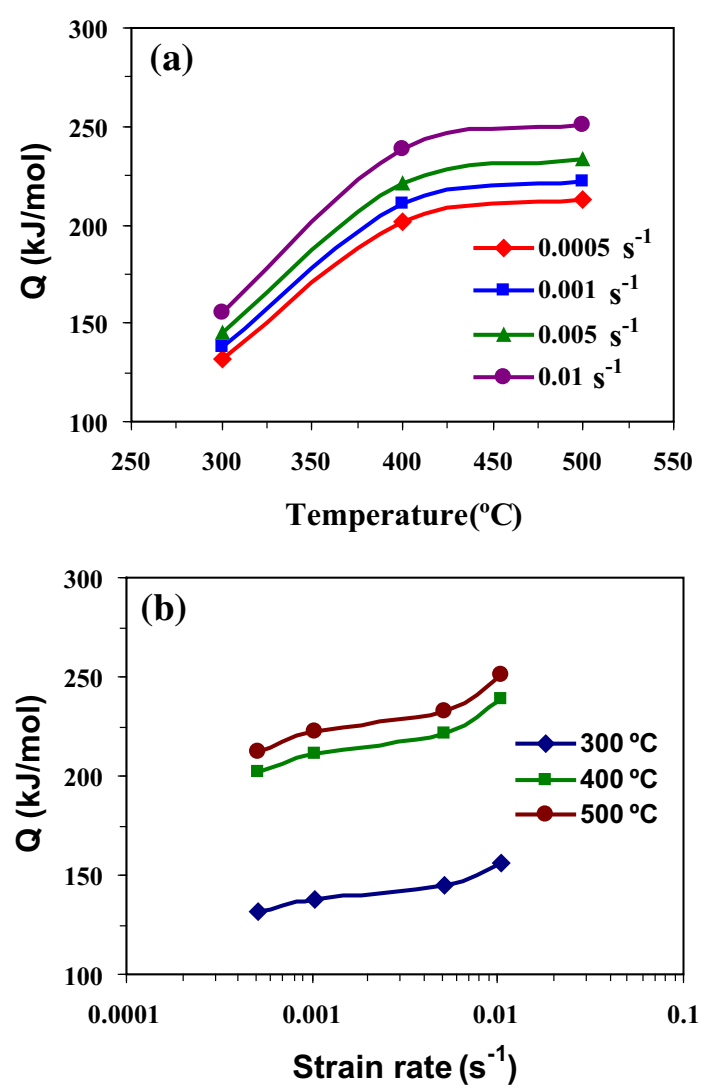

Fig. 9. Variation of activation energy with (a) temperature at various strain rates and (b) strain rate at various temperatures.

difference in the activation energy indicates the changes in deformation mechanisms. ${ }^{40,41}$ The mean value of activation energy of the deformed AA6061 $\left(196 \mathrm{~kJ} \mathrm{~mol}^{-1}\right)$ is higher than that of the self-diffusion of aluminum $\left(144 \mathrm{~kJ} \mathrm{~mol}^{-1}\right),{ }^{42}$ grain boundary diffusion $\left(84 \mathrm{~kJ} \mathrm{~mol}^{-1}\right),{ }^{16}$ and the dislocation pipediffusion in aluminum $\left(82 \mathrm{~kJ} \mathrm{~mol}^{-1}\right){ }^{43}$ Besides, it is known that GBS, a mechanism that does not take place at $20^{\circ} \mathrm{C}$ in $\mathrm{Al}$ or other structural metals, becomes active near $0.5 T_{\mathrm{m}}$ due to an activation energy much lower than that for climb, $Q_{\mathrm{GBS}} \approx 0.8 Q_{\mathrm{D}}$ for $\mathrm{Al} .{ }^{31}$ Therefore, the GBS or the dislocation climb cannot be a dominant mechanism for hot tensile deformation of the studied alloy. The obtained activation energy is similar to the activation energy for self-diffusion of aluminum at lower temperatures. The average activation energy of the studied alloy at $300^{\circ} \mathrm{C}$ and at different strain rates $\left(143 \mathrm{~kJ} \mathrm{~mol}^{-1}\right)$ is very close to that for the self-diffusion of $\mathrm{Al}\left(144 \mathrm{~kJ} \mathrm{~mol}^{-1}\right)$. In other words, this suggests that the dominant mechanism, at $300^{\circ} \mathrm{C}$ and the strain rates of $0.0005-0.01 \mathrm{~s}^{-1}$, can be controlled by dislocation climb. The apparent activation energy (greater than $200 \mathrm{~kJ} \mathrm{~mol}^{-1}$ ) at all strain rates and temperatures of $400^{\circ} \mathrm{C}$ to $500^{\circ} \mathrm{C}$ is higher than that at $300^{\circ} \mathrm{C}$. There may be abrupt changes in $Q_{\mathrm{HW}}$ as a result of changes in 
microstructure with temperature. In such a case, the occurrence of DRV or dynamic recrystallization, ${ }^{31}$ for example, can lead to different values of $Q$.

\section{CONCLUSION}

The hot deformation behavior of ECAP + coldrolled AA6061 alloy at different strain rates and temperatures was studied. The results show that the flow stress and hot formability of the alloy depend on the strain rate and temperature. According to the hot tensile test results, increasing the temperature led to shifting the superplasticity to higher strain rates. The great difference in the strain rate sensitivity of the undeformed and severe plastic deformed alloy indicates that the recovery of dislocations can be the dominant deformation mechanism. The constitutive equations pertaining to the hot deformation of ECAP + cold-rolled AA6061 alloy were developed.

\section{OPEN ACCESS}

This article is distributed under the terms of the Creative Commons Attribution License which permits any use, distribution, and reproduction in any medium, provided the original author(s) and the source are credited.

\section{REFERENCES}

1. S. Dadbakhsh, A. Karimi Taheri, and C.W. Smith, Mater. Sci. Eng., A 527, 4758 (2010).

2. Sh Ranjbar-Bahadori, K. Dehghani, and F. Bakhshandeh, Mater. Sci. Eng., A 583, 36 (2013).

3. V.V. Stolyarov, L. Zeipper, B. Mingler, and M. Zehetbauer, Mater. Sci. Eng., A 476, 98 (2008).

4. K.T. Park, H.J. Lee, C.S. Lee, W.J. Nam, and D.H. Shin, Scr. Mater. 51, 479 (2004)

5. Sh Ranjbar-Bahadori, K. Dehghani, and F. Bakhshandeh, Mater. Sci. Eng., A 588, 260 (2013).

6. K.T. Park, H.J. Lee, C.S. Lee, and D.H. Shin, Mater. Sci. Eng., A 393, 118 (2005).

7. V.V. Stolyarov, YTh Zhu, I.V. Alexandrov, T.C. Lowe, and R.Z. Valiev, Mater. Sci. Eng., A 343, 43 (2003).

8. K. Rahimi Mamaghani and M. Kazeminezhad, J. Mater. Eng. Perform. 23, 115 (2014).

9. V.L. Sordi, M. Ferrante, M. Kawasaki, and T.G. Langdon, J. Mater. Sci. 47, 7870 (2012).

10. I. Nikulin, R. Kaibyshev, and T. Sakai, Mater. Sci. Eng., A 407, $62(2005)$.

11. A.A. Khamei and K. Dehghani, Mater. Sci. Eng., A 41A, 2595 (2010).

12. A.A. Khamei and K. Dehghani, J. Alloy. Compd. 490, 377 (2010).
13. M. Vaseghi, A. Karimi Taheri, S.I. Hong, and H.S. Kim, Mater. Des. 31, 4076 (2010).

14. B. Verlinden, J. Driver, I. Samajdar, and R.D. Doherty, Thermo-Mechanical Processing of Metallic Materials, 1st ed. (New York: Elsevier, 2007).

15. G.E. Dieter, H.A. Kuhn, and S.L. Semiatin, Handbook of Workability and Process Design, 1st ed. (Materials Park, OH: ASM International, 2003).

16. W.J. Kim and S.J. Yoo, Scr. Mater. 61, 125 (2009).

17. W.J. Kim, J.K. Kim, T.Y. Park, S.I. Hong, D.I. Kim, Y.S. Kim, and J.D. Lee, Metall. Mater. Trans. A 33A, 3155 (2002).

18. W.J. Kim, Y.K. Sa, H.K. Kim, and U.S. Yoon, Mater. Sci. Eng., A 487, 360 (2008).

19. Ch Xu, M. Furukawa, Z. Horita, and T.G. Langdon, Acta Mater. 51, 6139 (2003).

20. R.B. Figueiredo, M. Kawasaki, C. Xu, and T.G. Langdon, Mater. Sci. Eng., A 493, 104 (2008).

21. Y.G. Ko, C.S. Lee, D.H. Shin, and S.L. Semiatin, Metall. Mater. Trans. A 37A, 381 (2006).

22. F. Mushin, R. Kaibyshev, Y. Motohashi, and G. Itoh, Metall. Mater. Trans. A 35A, 2383 (2004).

23. E. Avtokratova, O. Sitdikov, M. Markushev, and R. Mulyukov, Metall. Mater. Trans. A 538, 386 (2012).

24. A.R. Salehi, S. Serajzadeh, and N. Yazdipour, Mater. Chem. Phys. 101, 153 (2007).

25. T.G. Langdon, J. Mater. Sci. 44, 5998 (2009).

26. D.H. Shin, D.Y. Hwang, Y.J. Oh, and K.T. Park, Metall. Mater. Trans. A 35A, 825 (2004).

27. H. Watanabe, T. Mukai, and K. Higashi, Metall. Mater. Trans. A 39A, 2351 (2008).

28. Y. Miyahara, K. Matsubara, Z. Horita, and T.G. Langdon, Metall. Mater. Trans. A 36A, 1705 (2005).

29. K.T. Park, D.Y. Hwang, Y.K. Lee, Y.K. Kim, and D.H. Shin, Mater. Sci. Eng., A A341, 273 (2003).

30. M. Karami and R. Mahmudi, Mater. Des. 53, 534 (2014).

31. M. Karami and R. Mahmudi, Mater. Sci. Eng., A 576, 156 (2013).

32. M. Karami and R. Mahmudi, Mater. Lett. 81, 235 (2012).

33. K. Dehghan and A.A. Khamei, Mater. Sci. Eng., A 527, 684 (2010).

34. H. Farnoush, A. Momeni, K. Dehghani, M.J. Aghazadeh, and H. Keshmiri, Mater. Des. 31, 220 (2010).

35. A. Momeni, K. Dehghani, and X.X. Zhang, J. Mater. Sci. 47, 2966 (2012)

36. Y.C. Lin, Y. Ding, M.S. Chen, and J. Deng, Mater. Des. 52 , 118 (2013).

37. B. Meng, M. Wan, X. Wu, Y. Zhou, and Ch Chang, Int. J. Refract. Met. Hard Mater. 45, 41 (2014).

38. M. Zhou, Y.C. Lin, J. Deng, and Y.Q. Jiang, Mater. Des. 59 , 141 (2014).

39. J. Luo, M. Li, H. Li, and W. Yu, Mater. Sci. Eng., A 505, 88 (2009).

40. Y. Liu, R. Hu, J. Li, H. Kou, H. Li, H. Chang, and H. Fu, Mater. Sci. Eng., A 497, 283 (2008).

41. F. Ma, W. Lu, J. Qin, and D. Zhang, Mater. Lett. 60, 400 (2006).

42. E.A. Brandes and G.B. Brook, Smithells Metals Reference Book, 7th ed. (New York: Elsevier, 1992).

43. I.C. Hsiao and J.C. Huang, Metall. Mater. Trans. A 33A, $1373(2002)$ 